\title{
REPRESENTACIONES SOCIALES SOBRE LA ENSEÑANZA DEL CONFLICTO EN EL PROFESORADO COLOMBIANO: ALGUNOS EFECTOS EN SUS DECISIONES DIDÁCTICAS
}

\author{
Social Representations on the Teaching of the Conflict in \\ Colombian Teachers: Some Effects on their Didactic Decisions
}

\begin{abstract}
Isabel Jiménez Becerra*
Universidad de La Salle. Colombia

ijimenez@unisalle.edu.co | https://orcid.org/0000-0003-4263-1970
\end{abstract}

Fecha de recepción: 07/04/2021

Fecha de aceptación: 09/11/2021

Acceso anticipado: 04/01/2022

Resumen: El artículo expone los resultados de una investigación centrada en identificar, describir y analizar las representaciones sociales sobre el conflicto del profesorado colombiano y sus efectos sobre las decisiones didácticas, a partir de tres núcleos de análisis: las representaciones sociales, el diseño de las clases de Ciencias Sociales y las prácticas de enseñanza. Desde una investigación cualitativa de alcance descriptivo, enmarcada en la teoría fundamentada, se trabajó con una muestra a conveniencia de diez profesores ubicados en zonas geográficas rurales y urbanas de Colombia. Las representaciones sociales mapeadas fueron diversas, como producto de la variedad de conflictos sociales en los que se encuentra inmerso el escenario escolar del país. Dentro de las conclusiones se proponen algunos modelos didácticos posibles para la enseñanza del conflicto, que articulan la

* Doctora Cum Laude en Educación en la Línea Didáctica de la Historia, la Geografía y las Ciencias Sociales de la Universidad Autónoma de Barcelona. Investigadora categoría Asociado (MINCiencias - Colombia) en temas en Didáctica de las Ciencias Sociales, TIC e Innovación. Profesora de Planta Categoría Asociado II, metodóloga, didácta e investigadora del Doctorado Educación y Sociedad de Universidad de La Salle (Bogotá - Colombia) en la línea Educación Ciudadana, Ética y Política para la Paz. 
memoria histórica, el conocimiento del medio, las problemáticas de contexto y un aporte al desarrollo del pensamiento crítico creativo.

Palabras clave: conflicto social; didáctica; representación social; memoria histórica; pensamiento crítico creativo.

Abstract: The article presents the results of a research focused on identifying, describing and analyzing the social representations on the conflict of the Colombian teachers and its effects on the didactic decisions, from three analysis nuclei: the social representations, the design of the classes of Social Sciences and the practices of teaching. From a qualitative research of descriptive scope, framed in the grounded theory, we worked with a sample at convenience of ten teachers located in rural and urban geographical areas of Colombia. The social representations mapped were diverse, as a result of the variety of social conflicts in which the country's school scene is immersed. The conclusions propose some possible didactic models for the teaching of conflict, which articulate historical memory, knowledge of the environment, context issues and a contribution to the development of creative critical thinking.

Keywords: social conflict; didactics; social representation; historical memory; critical creative thinking.

Sumario: 1. Introducción; 2. Metodología; 3 . Análisis de resultados; 3.1. Fase código sustantivo abiertos - muestreo teórico: el pensamiento de los profesores sobre la enseñanza del conflicto colombiano; 3.2. Fase código «in vivo»-axial - «¿Qué dice que hace el profesorado sobre la enseñanza del conflicto colombiano?»; 3.3. Fase Codificación selectiva - ¿Qué hace el profesorado? una radiografía a partir de la observación de la planificación y la implementación de las prácticas de enseñanza; 4 . Discusión; 4.1. ¿Cuáles son los aportes y las conclusiones de esta investigación sobre la enseñanza del conflicto colombiano en los maestros de Ciencias Sociales?; 5. Referencias bibliográficas.

\section{INTRODUCCIÓN}

¿Es válido hablar de posconflicto en Colombia? ¿Está preparada la escuela para esto? La sociedad de este país debe considerar que este escenario complejo no culmina con la firma de los acuerdos con las Fuerzas Armadas Revolucionarias de Colombia-Ejército del Pueblo o FARC-EP, uno de los grupos armados de mayor impacto en la historia de la violencia de este país. Los acuerdos no representan una consecución automática de la paz porque, según las circunstancias actuales, aún es necesario resolver diversos conflictos de carácter bélico, así como superar las varias y cruentas violencias que sacuden el territorio.

La paz sólida hay que construirla desde la ejecución cabal de las tareas del posconflicto y la reconciliación que incluye, tal como lo Rodríguez (2016), la reincorporación de los alzados en armas, la reparación de las víctimas, la aplicación de la justicia transicional y el restablecimiento de los derechos humanos de las poblaciones, 
grupos sociales y personas que sufrieron alguna vulneración. De forma paralela, resulta imprescindible emprender las reformas económicas, sociales y políticas que el país requiere e iniciar la construcción de una nueva cultura: la cultura de paz (Fisas, 1998). Además de avanzar en los acuerdos con otros grupos armados, así como en las acciones para la prolongación y el respeto de tales pactos.

Justamente, a la educación le corresponde el reto de preparar la conciencia y los sentimientos de las nuevas generaciones para convivir de manera pacífica, es decir, enseñar los principios y valores de la coexistencia armónica y solidaria. Por esta razón, el papel del profesorado se centra en contribuir a la enseñanza y las prácticas escolares, erradicando de la conciencia de los futuros ciudadanos las representaciones sociales reaccionarias propias de la vieja cultura de la guerra para reemplazarlas por los principios, valores e idearios de la cultura de la paz.

Entonces, surgen preguntas basadas en indagar qué representaciones posee el profesorado sobre el conflicto y cómo estás pueden afectar las decisiones didácticas de la enseñanza de la paz ${ }^{1}$. Desde el reconocimiento del conflicto, a la luz de su saber histórico, es posible la comprensión de su origen, estado actual y, por lo tanto, el papel que deben asumir los futuros ciudadanos para abordarlo de manera más asertiva dentro de los diferentes escenarios que constituyen su cotidianidad.

Una situación que generó diversos interrogantes sobre la educación del conflicto armado en Colombia se desató como consecuencia de los resultados obtenidos en el plebiscito para la implementación de los acuerdos, logrados en el 2016 entre las FARC y el Gobierno Nacional. Según los datos brindados por la Registraduría Nacional del Estado Civil, el «NO» ganó con el 50,21 \% frente a un 49,78 \% que optó por el «Sí». En efecto, es difícil comprender las razones por las que parte de los ciudadanos rechazó el fin del conflicto armado, teniendo en cuenta que se trata de una condición histórica que data de hace más de medio siglo y, cuyo trayecto ha cobrado la vida de más de 200000 personas.

Sin duda, el mundo quedó perplejo ante los resultados, dado que diferentes naciones esperaban dar la bienvenida al fin de la guerra en Colombia. Esta circunstancia puso en evidencia que el anhelo de paz era más un entusiasmo internacional que una auténtica voluntad de la mayoría de los colombianos. Cuestión que se ratifica con la tasa de abstención electoral que llegó al 63 \%, como una de las más altas durante las últimas décadas. Así, al indagar sobre las razones por las cuales ganó el «NO», muchos de los colombianos manifestaron, ante diferentes medios de

1 Tesis dirigida e inspirada en las investigaciones hechas por el Dr. Joan Pagès Blanch (q. e. p. d.). Licenciado en Filosofía y Letras; Doctor en Ciencias de la Educación - Profesor de didáctica de las Ciencias Sociales en la Universidad Autónoma de Barcelona desde 1977. Fue decano de la Facultad de Ciencias de la Educación, director del departamento de Didáctica de la Lengua, de la Literatura y de las Ciencias Sociales en varias etapas. Se especializó en temas curriculares en especial en enseñanza y didáctica de la historia y en educación para la ciudadanía. 
comunicación, que las heridas de la guerra con las FARC seguían demasiado abiertas: no es posible hablar de reconciliación sin existir la justicia y reparación.

Esta postura permite reflexionar sobre si la decisión de los colombianos es resultado de unas prácticas educativas que tienden a avivar el conflicto, en ocasiones, a través del fomento de la intolerancia, los prejuicios y la injusticia. Dentro de esta consideración, se propuso un marco conceptual basado en tres aspectos claves para analizar en la investigación: el primero se centró en el conflicto como objeto de estudio, identificando si la enseñanza de la historia se integra con la realidad de quienes se enseña. El segundo fue analizar el efecto de las decisiones didácticas para la enseñanza del conflicto que asume el profesorado, a partir de su pensamiento y el conocimiento social que posee sobre este. Finalmente, la revisión sobre los temas de formación inicial del profesorado y su relación con las prácticas de enseñanza sobre el conflicto.

El primer aspecto, sobre conflicto como objeto de estudio, se analizó desde el marco de la conflictología ${ }^{2}$ donde se encontraron autores como Vinyamata (2001) con su propuesta basada en el análisis y resolución de conflictos. También, Schellenberg (1982), Dukes (1999) y Mitchell (1969) con sus aportes desde el paradigma de la complejidad. Al ahondar en estas propuestas, se precisó en los diversos andamiajes que llevan a reflexionar, en el contexto de la escuela, el valor de la enseñanza del conflicto y sus aplicaciones en la práctica.

Como referente central se tomaron la teoría de Redorta (2004), quien coincide con las posturas del investigador Fisas ${ }^{3}$ (1987), desde la necesidad de abanderar a la escuela para lograr una asertiva educación en la cultura de paz. Su papel es enseñar a tratar positivamente los conflictos, al minimizar el espacio de la violencia. Esto incluye las políticas preventivas sobre los conflictos armados, dado que cuando estos ya han estallado, todos los esfuerzos de negociación para terminarlos deben ser mediante el diálogo.

Al respecto, Pagès (1997) plantea la importancia de representar y enseñar los mismos desde una posición creativa, al entender que éste puede ser capaz de impulsar pensamientos y acciones colectivas destinadas a la transformación auténtica de la realidad. Asimismo, Coser (1972) los descifra a partir de las funciones que cumple dentro de una interpretación significativa que les permite

2 La conflictología es la ciencia del conflicto. Conocimientos, métodos y técnicas para abordar los conflictos de forma no violenta. Uno de sus elementos principales es la aproximación al conflicto de forma holística, global, como un todo, alejado de la simplificación de las cosas. Desde las concepciones tradicionales se fragmenta el mundo, la realidad y el conflicto. En la conflictología, no se fragmenta la realidad, no se reduce a un fenómeno de una sola variable o a ser abordado desde la mirada de una sola disciplina o profesión (Jiménez, 2018b).

3 Doctor en estudios de paz de la Universidad de Bradford, editor del Manual de procesos de paz, director de la l'Escola de la PAU, la Escuela de la Paz de la Universidad Autónoma de Barcelona y autoridad mundial en análisis de conflictos y procesos de paz. 
a los actores sociales comprender los problemas reales del presente y analizar el papel del ciudadano en ellos.

Este planteamiento permite analizar que las propuestas de Coser (1972), Pagès (1997), Calderón (2009), Galtung (2003) y Lederach (1984) tienen una conexión con la psicología social que, a su vez, concuerda con algunos de los postulados de la teoría crítica, cuyo valor reside, en el marco de esta investigación, en la función que posee frente a la enseñanza del conflicto. Esto implica que tales temáticas como nicho didáctico sea lograr que los contenidos de la enseñanza de las Ciencias Sociales se utilicen para la comprensión de la situación histórico cultural de la sociedad y aprender a intervenir en su resolución de manera pacífica.

En cuanto al segundo aspecto que analizó la investigación, desde el efecto de las decisiones didácticas para la enseñanza a partir del pensamiento y conocimiento social de los docentes, los componentes encontrados se clasificaron en: la enseñanza del conflicto a partir de los programas curriculares, el valor de los procesos de reflexión que posee el profesorado sobre la enseñanza del conflicto centrada en los métodos, contenidos y los recursos. Además, las representaciones sociales que influyen en sus prácticas y el impacto que generan sobre las decisiones didácticas.

El componente relacionado con la enseñanza del conflicto, a partir de los programas curriculares y el valor de los procesos de reflexión que posee el profesorado para su abordaje, se delimita en la línea que Pagès (2002) define como las investigaciones sobre la programación de las Ciencias Sociales por parte de estos actores. Esta perspectiva analiza las prácticas de enseñanza del área y la manera cómo los futuros docentes reflejan sus representaciones sobre la labor pedagógica que realizan. Autores como Adler (2008) y Evans (1994) plantean que el conocimiento curricular de los profesores sobre el tema, sus concepciones $y$, por ende, su labor en el aula, tienden a ser estereotipados y poco reflexionados dentro de las clases.

En los métodos, contenidos y recursos orientados por el uso de manuales, González (2014) y Jara (2010) coinciden en analizar la transposición didáctica de la enseñanza del conflicto inmersa en los libros texto y su relación con la realidad. El libro descentra el valor de las experiencias y excluye la representación social de la realidad propia de niños y maestros. De igual forma, Parra (2011) y Bravo (2002) identifican la carencia de decisiones didácticas para abordar el tema, al considerar la necesidad de generar espacios donde el profesorado reconozca cómo enfrentar estas situaciones cotidianas, en tanto recurso vital para la enseñanza de las Ciencias Sociales y la comprensión del contexto a partir de la realidad de quien aprende.

Sobre el papel de las representaciones sociales que influyen en sus prácticas y en las decisiones didácticas, Evans (1994) indagó la manera en que las concepciones, creencias y perspectivas del profesorado tienen un impacto en la enseñanza de las Ciencias Sociales. Por su parte, Santisteban (2005) reafirma la importancia del análisis de las representaciones sociales y plantea la necesidad de indagar sobre las 
prácticas de enseñanza. Otros aportes al tema han sido realizados por Abric (1996), desde los juicios, conflictos y representaciones sociales, así como la propuesta de Thornberg (2010) sobre estas últimas y su relación con la violencia.

Al describir los escenarios para la enseñanza del conflicto, Salinas e Isaza (2003) platearon estrategias didácticas para educar en el valor de la justicia, a partir de las representaciones sociales. Los recursos didácticos propuestos se centraron en el uso de las casuísticas, que permitían a los participantes hacer un balance frente a los derechos. Esto coincide con las investigaciones hechas por Pagès y Oller (2007) en España, desde las representaciones que tienen el alumnado sobre el derecho, la justicia y la ley.

Finalmente, el tercer aspecto abordó los temas de formación inicial del profesorado y la relación con las representaciones sociales y las prácticas de enseñanza del conflicto. Desde ahí, se reconoce la postura de Moscovici (2000) y Jodelet (2013) sobre representación social, donde se plantea que "en el estudio, del cómo y del porqué la gente comparte conocimiento y construye su realidad común, de cómo ellos transforman ideas en prácticas - un mundo del poder de las ideas- es un problema específico de la psicología social» (Moscovici, 2000, p. 2).

La representación social del conflicto tiende a una objetivación producto, únicamente, de la percepción del contexto y su experiencia derivada de un saber cultural, sin ningún tipo de rigor científico que surja, bien sea de su formación en Ciencias Sociales o de la solvencia frente al manejo y conceptualización del pensamiento histórico. En consecuencia, al vincular estas representaciones con la enseñanza y el aprendizaje de contenidos sociales, cabe analizar: ¿en qué consiste preparar para ser profesor o profesora de historia? ¿qué implica desarrollar las competencias en didáctica de la historia de los futuros maestros?

Al respecto, Pagès $(1996,1999,2002)$ evidencia el vínculo con el reconocimiento de las concepciones, creencias o perspectivas y su impacto en las prácticas de enseñanza, donde se ha evidenciado una ruptura entre las representaciones y el ejercicio pedagógico del maestro. Adler (1991) y Avery (2010) analizan el tema desde la formación y su relación con el profesional reflexivo. Evans (2006) ahonda en temas como las finalidades de la enseñanza de las Ciencias Sociales, así como el análisis sobre la formación inicial del profesorado en esta área, las investigaciones sobre las representaciones sociales y su efecto en el diseño de las clases y las decisiones didácticas (Jiménez y Segovia, 2020).

Un elemento importante en el estudio sobre representaciones sociales y prácticas de enseñanza del conflicto el marco de las Ciencias Sociales fue la revisión hecha a las investigaciones doctorales ubicadas en Grup de Recerca en Didàctica de les Ciències Socials (GREDICS) de la Universidad Autónoma de Barcelona. En la línea de investigación sobre la formación inicial de maestros y profesorado se identificó el predominio de una enseñanza centrada en la apropiación de conocimientos generales y específicos, así como en el desarrollo de competencias y saberes propios 
del área. No obstante, no se halló ninguna estrategia didáctica para el abordaje del conflicto en el aula.

Esto lo evidencian algunas investigaciones de diferente procedencia y tradiciones, entre las que se destacan los estudios de naturaleza anglosajona (Adler, 1993; 2008; Adler y Goodman, 1983; Ross, 1987; Shaver, 2001), francófona (Audigier, 2002; Tutiaux-Guillon, 2003), nórdica (Virta, 2002, 2009), española (Pagès, 1999, 2002; Capella, 2004; Llobet, 2005; Santisteban, 2005; 2009) y latinoamericana (Bravo, 2002; Jara, 2010).

En Colombia existe un bajo reporte de investigaciones enmarcadas en la enseñanza del conflicto desde la teoría critica de las Ciencias Sociales. El análisis de este tipo de enseñanza ha sido realizado por el campo de la psicología educativa desde temas como el clima escolar, el manejo del conflicto en la escuela, el análisis de sus factores y la convivencia en el aula.

\section{METOdOLOGÍA}

La investigación se orientó a reconocer el papel del docente y sus prácticas de enseñanza en torno al conflicto colombiano. A partir de ahí, se buscó reflexionar y hallar respuestas a preguntas relacionadas con el abordaje de este tema para descifrar representaciones sociales (Abric, 2001) como: ¿qué piensan los profesores sobre este?, ¿qué dicen?, ¿qué saben?, ¿qué representaciones tienen?, ¿dónde las aprenden?, ¿saben qué deben enseñar sobre el tema?, ¿lo enseñan?, ¿cómo lo enseñan?, ¿para qué lo enseñan? Al dar respuesta a estas preguntas se podrá analizar su enseñanza con el propósito de plantear, proponer o modificar prácticas alternativas que enriquezcan la didáctica de su estudio.

Desde una investigación cualitativa, con alcance cualitativo autorreflexivo continuo (Lewin, 1988; Carr y Kemmis, 1997; Denzin y Lincoln, 2012), enmarcada en el paradigma sociocrítico y la teoría fundamentada, se abordó una explicación conceptual sobre un problema central que aborda el grupo de estudio: las formas de enseñanza del conflicto social a partir de las representaciones sociales de los docentes colombianos. Ateniendo a los postulados de la teoría fundamentada, la obtención de datos fue un proceso semiestructurado, abierto y exploratorio aplicado por fases del diseño para recolectar, de forma ordenada y sistemática, la información, traduciendo cada instrumento en un apartado propio.

En la fase titulada "código sustantivo abiertos - muestreo teórico», cuyo objetivo fue mapear «el pensamiento de los profesores sobre la enseñanza del conflicto colombiano", se implementó como técnica un cuestionario (Wagner y Hayes, 2011), siendo su instrumento de recolección una encuesta en línea. Posteriormente, para la fase de código «in vivo» axial sobre "¿qué dice que hace el profesorado sobre 
la enseñanza del conflicto colombiano?», se utilizó la entrevista (Taylor y Bogdan, 1992) desde un cuestionario.

En cuanto a la fase de codificación selectiva, que emerge de las teorías que permiten contrastar lo que dice y hace el profesorado, permitió plantear el apartado «¿Qué hace el profesorado? Una radiografía a partir de la observación de la planificación de la clase y la implementación de las prácticas de enseñanza del conflicto colombiano». La técnica utilizada para este momento de la investigación se centró en la observación no participante (Angrosino, 2012; Rodríguez, 2007), recolectada datos a partir de instrumentos como los memorándums (Flick, 2007) y organizadas en diversas matrices de recolección de datos a partir de modelos de análisis que permitió contrastar los respectivos resultados de formar organizada. El resumen de la experiencia metodológica implementada en este diseño se resume en la Figura 1.

Como producto de la recolección, análisis y contraste de cada una de esta fase se logró saturar todas las propiedades y dimensiones hasta generar la categoría central representación social en el marco de la enseñanza del conflicto por parte de los maestros. Esto se logró gracias a las deducciones generadas en la aplicación de las entrevistas y en los resultados del cuestionario, dado que las narrativas de los participantes ofrecían el máximo de propiedades planteadas para extraer códigos y categorías sobre la enseñanza del conflicto colombiano.

En cuanto a la población, el muestreo teórico, como técnica de selección de los participantes de esta investigación, emerge a partir de los maestros seleccionados en la implementación de la primera fase de la investigación titulada "Código sustantivo abiertos - muestreo teórico", cuyo objetivo mapear el pensamiento de los profesores sobre la enseñanza del conflicto colombiano. A partir de ahí, se logró identificar y clasificar el perfil de los profesores ${ }^{4}$, caracterizados por ser profesionales en Licenciados en Ciencias Sociales y con su trabajo orientado a la enseñanza en Básica Primaria en algunas escuelas colombianas.

${ }^{4}$ Un aspecto por indagar sobre el perfil del profesorado tiene que ver el efecto que puede generar, en las prácticas de enseñanza, que su formación de base no esté en el marco de la formación en las Ciencias de la Educación o licenciaturas (conocidas así en Colombia para aquellas personas que deciden asumir la profesión docente). Por otro lado, la variedad de los perfiles encontrados en los profesores de Básica Primaria es producto del Decreto Ley 1278 de 2002, donde se establece que en Colombia los profesionales no licenciados están legalmente habilitados para ejercer la función docente y pueden ser profesionales de la educación. A partir de esta realidad, es clave ahondar en el análisis de aspectos que hacen parte de la didáctica de las Ciencias Sociales, tales como el manejo disciplinar del área, la formación en la profesionalización en educación y las representaciones sociales, a partir de sus experiencias sobre los procesos de enseñanza de temas como el conflicto. 
Tabla 1. Enfoque, diseño, técnicas e instrumentos

\begin{tabular}{|c|c|c|c|c|c|}
\hline \multicolumn{2}{|c|}{ Enfoque } & \multicolumn{4}{|c|}{$\begin{array}{l}\text { Cualitativo de espiral autorreflexivo continuo (Lewin, 1988; } \\
\text { Carr y Kemmis, 1997; Denzin y Lincoln, 2012) y de paradigma } \\
\text { sociocrítico. }\end{array}$} \\
\hline \multicolumn{2}{|c|}{ Diseño } & \multicolumn{4}{|c|}{ Teoría fundamentada (Strauss y Corbin, 2002). } \\
\hline \multicolumn{2}{|c|}{$\begin{array}{l}\text { Fases de la investigación } \\
\text { a partir de la «matriz } \\
\text { condicional/consensual») } \\
\text { (Strauss y Corbin, 2002). }\end{array}$} & \multicolumn{4}{|c|}{$\begin{array}{l}\text { El diseño teoría fundamentada es relevante por su capacidad } \\
\text { para generar otras teorías y porque brinda la posibilidad de tratar, } \\
\text { sistemáticamente, información cualitativa y cuantitativa, logrando } \\
\text { ser un diseño mixto por los instrumentos que intervienen. Strauss } \\
\text { y Corbin (2002) plantearon una vertiente de este diseño conocida } \\
\text { como teoría fundamentada Straussiana. }\end{array}$} \\
\hline \multicolumn{2}{|c|}{$\begin{array}{l}\text { Código sustantivo abiertos. } \\
\text { Muestreo teórico }\end{array}$} & \multicolumn{2}{|c|}{ Código «in vivo» - Axial } & \multicolumn{2}{|c|}{ Codificación selectiva } \\
\hline \multicolumn{2}{|c|}{$\begin{array}{l}\text { Teoría generada } \\
\text { «El pensamiento de los profe- } \\
\text { sores sobre la enseñanza del } \\
\text { conflicto colombiano» }\end{array}$} & \multicolumn{2}{|c|}{$\begin{array}{c}\text { Teoría generada } \\
\text { «¿Qué dice que hace el profe- } \\
\text { sorado sobre la enseñanza del } \\
\text { conflicto colombiano?» }\end{array}$} & \multicolumn{2}{|c|}{$\begin{array}{c}\text { Teoría generada } \\
\text { «¿Qué hace el profesorado? } \\
\text { Una radiografía a partir de la } \\
\text { observación de la planifica- } \\
\text { ción de la clase y la imple- } \\
\text { mentación de las prácticas } \\
\text { de enseñanza del conflicto } \\
\text { colombiano» }\end{array}$} \\
\hline Técnicas & Cuestionario & Técnicas & Entrevista & Técnicas & $\begin{array}{l}\text { Observación } \\
\text { no partici- } \\
\text { pante }\end{array}$ \\
\hline \multirow[t]{2}{*}{ Instrumentos } & \multirow[t]{2}{*}{$\begin{array}{c}\text { Formulario en } \\
\text { drive }\end{array}$} & \multirow[t]{2}{*}{ Instrumentos } & \multirow[t]{2}{*}{ Cuestionario } & \multirow[t]{2}{*}{ Instrumentos } & $\begin{array}{l}\text { Notas o me- } \\
\text { morándums }\end{array}$ \\
\hline & & & & & $\begin{array}{l}\text { Matrices de } \\
\text { recolección de } \\
\text { datos a partir } \\
\text { de modelos } \\
\text { de análisis } \\
\text { centrados en } \\
\text { la teoría de la } \\
\text { Didáctica de } \\
\text { las Ciencias }\end{array}$ \\
\hline
\end{tabular}

Fuente: Jiménez, 2020b.

Es importante considerar que la razón principal de tomar estos docentes como una muestra por juicio o intencionada (Krause, 2003) obedece a las respuestas obtenidas sobre su práctica, así como la relación con los tipos de conflictos en los que está inmersa su escuela, relacionadas con el tema de la enseñanza del conflicto, las representaciones sociales y cómo el factor de contexto puede impactar en sus experiencias. La Figura 1 representa las zonas geográficas colombianas de carácter rural y urbano en las que estaban ubicados los profesores objeto de estudio, así como sus perfiles profesionales. 
Figura 1. Características de la población y muestra

Figura 1. Contextos geográficos de las instituciones educativas

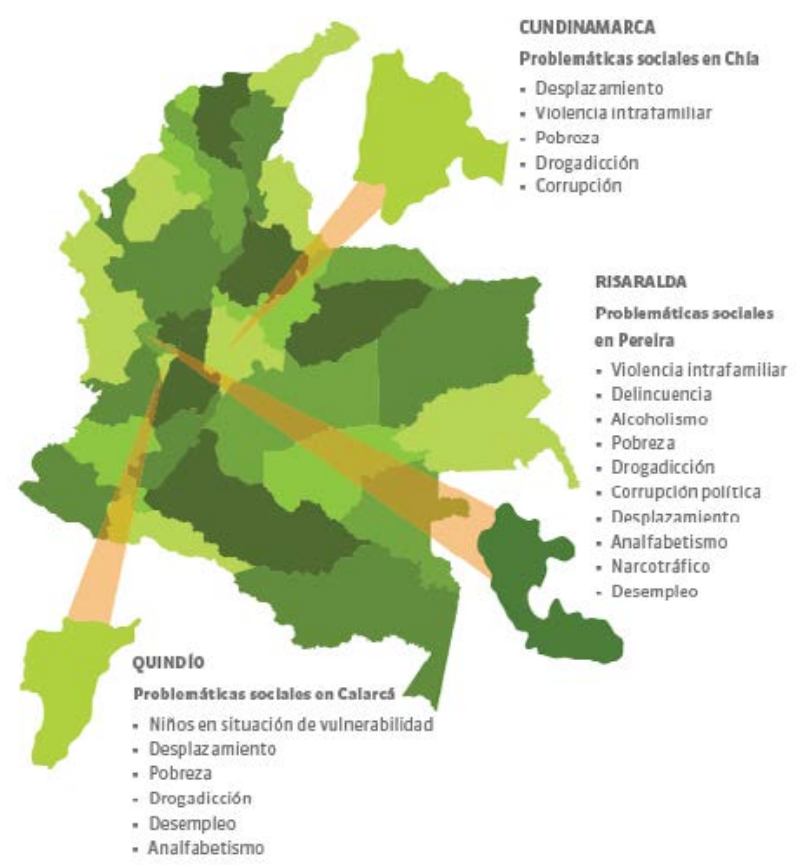

Caracterizacióny perfil de los profesores participant es de la investigación.

\begin{tabular}{|c|c|c|c|c|}
\hline \multicolumn{3}{|c|}{$\begin{array}{l}\text { Universidad Tecnológica de Pereira -UTP } \\
\text { Pereira-Ris aralda }\end{array}$} & \multicolumn{2}{|c|}{$\begin{array}{l}\text { Universidad de La Sabana } \\
\text { Chia - Cundinamarca }\end{array}$} \\
\hline $\begin{array}{c}\text { Entrevistas } N^{\circ} 1 \text { PEREI. } \\
\text { RA, } \\
\text { RISARALDA } \\
\text { ZONA URBANA }\end{array}$ & $\begin{array}{c}\text { Entrevistas } N^{\circ} 2 \\
\text { CALARCA, } \\
\text { QUINDIO } \\
\text { ZONA RURAL }\end{array}$ & $\begin{array}{c}\text { Entrevistas } N^{\circ} 3 \\
\text { PEREIRA } \\
\text { RISARALDA } \\
\text { Z ONA URBANA }\end{array}$ & $\begin{array}{c}\text { Entrevistas } N^{\circ} 4 \\
\text { CHIA } \\
\text { CUNDINAMARCA } \\
\text { ZONA URBANA }\end{array}$ & $\begin{array}{c}\text { Entrevistas } N^{\circ} \mathbf{5} \\
\text { CHIA } \\
\text { CUNDINAMARCA } \\
\text { Z ONA RURAL }\end{array}$ \\
\hline \multicolumn{5}{|c|}{ FORMACON PREGRADUAL } \\
\hline $\begin{array}{l}\text { Lic. } \\
\text { Etnoeducacióny } \\
\text { Desarrollo } \\
\text { Comunitario }\end{array}$ & $\begin{array}{l}\text { Lic. en Tecnología } \\
\text { Educativa }\end{array}$ & $\begin{array}{l}\text { Lic. en } \\
\text { Etnoeducación }\end{array}$ & $\begin{array}{l}\text { Lic. } \\
\text { Ciencias Sociales }\end{array}$ & $\begin{array}{l}\text { Lic. en Básica Secundaria } \\
\text { con Especialidad en Cient } \\
\text { cias Sociales } \\
\text { Profesora } \\
\text { perteneciente } \\
\text { alresguardo } \\
\text { indigena }\end{array}$ \\
\hline & & FORMACON POSGR & DUAL & \\
\hline $\begin{array}{l}\text { Estudiante } 4 \text { to semestre } \\
\text { Maestría en Educacion } \\
\text { con Ilinea de } \\
\text { Didáctl cadelas Clencias } \\
\text { Sodales }\end{array}$ & $\begin{array}{l}\text { Estudiante } 4 \text { to semestre } \\
\text { Maestrla en Educacion } \\
\text { con Ifnea de } \\
\text { Didácticade las Clencias } \\
\text { Sociales }\end{array}$ & $\begin{array}{l}\text { Estudiante 4to semestre } \\
\text { Maestría en Educaxión } \\
\text { con Ifnea de } \\
\text { Didáctica-de las Clendas } \\
\text { Sociales }\end{array}$ & $\begin{array}{l}\text { Estudiante } 4 \text { to semestre } \\
\text { Maestría en Proyectos } \\
\text { Educativos } \\
\text { mediados por TK }\end{array}$ & $\begin{array}{l}\text { Estudiante 4to semestre } \\
\text { Maestría en Estudios } \\
\text { Artisticos } \\
\text { Estudia una } \\
\text { simul tá neamente en la Uni- } \\
\text { versidad Distrital Francisco } \\
\text { Joséde Caldas } \\
\text { Bogotá, } \\
\text { Cundina marca }\end{array}$ \\
\hline
\end{tabular}

Fuente: elaboración propia. 
De los 73 profesores participantes en la primera fase de la investigación, pertenecientes a los estudios de formación en Maestría en Educación, el primer grupo de la Universidad Tecnológica de Pereira (UTP) dentro de la Maestría en Educación en la línea de Didáctica de las Ciencias Sociales. El segundo grupo estaba conformado por estudiantes de la Universidad de La Sabana de Bogotá, en el contexto de la Maestría en Proyectos Educativos mediados por TIC y pertenecientes al proyecto de investigación ${ }^{5}$ dirigida por la investigadora autora de este artículo titulado. De este filtro quedaron 10 profesores que clasificaban para esta investigación por su perfil. Solo cinco aceptaron libremente ser entrevistados y observados.

\section{ANÁLISIS DE RESULTADOS}

A continuación, se presentan los resultados obtenidos en la implementación de la investigación, organizadas a partir de las fases de la teoría fundamentada (Strauss y Corbin, 2002). También, desde los datos extraídos de las técnica e instrumentos de investigación encargados de dar paso a los apartados sobre: qué piensa, dice y hace el profesorado sobre la enseñanza del conflicto colombiano.

\subsection{Fase código sustantivo abiertos - muestreo teórico: el pensamiento de los profesores sobre la enseñanza del conflicto colombiano}

Esta fase tuvo como propósito obtener una primera aproximación sobre el pensamiento y las representaciones sociales que poseen los profesores sobre tema del conflicto en Colombia. Para lograr este objetivo, se utilizó un cuestionario. La elección de esta técnica se ha basado en el análisis de datos cuantitativos, en el marco de la estadística descriptiva, dado que permite mostrar cómo algún hecho social se refleja en el pensamiento de los participantes; en este caso, el de algunos profesores de básica primaria ubicados en diversos contextos colombianos.

El cuestionario se construyó a partir de unas tipologías que permitieron el análisis de las prácticas de enseñanza, además de concretar el orden de los apartados de este capítulo de la siguiente forma: a. Caracterización de la formación que poseen los profesores de básica primaria, b. Las representaciones sociales sobre las

${ }^{5}$ El proyecto de investigación titulada Didácticas innovadoras mediadas por TIC: retos a partir de la ecología del aprendizaje (Jiménez, 2018) se ha desarrollado desde el año 2015. Su directora ha dirigido y acopiado allí los resultados de investigación de 50 instituciones de educación y dos del sector corporativo del contexto colombiano. Producto de los resultados obtenidos, se han generado un análisis centrado en identificar las finalidades y funciones de las técnicas de enseñanza, las metodologías y su relación con la concepción de currículum que poseían los investigadores; así como la gestión institucional y la formación del profesorado para la aprehensión y uso de las TIC en su quehacer pedagógico. 
finalidades de la enseñanza de las Ciencias Sociales y c. La planificación de las clases y las estrategias que implementan, considerando el interés puesto sobre el conflicto en tanto contenido a enseñar. En la Tabla 2 se resumen los respectivos núcleos y el número de preguntas planteadas.

Tabla 2. Núcleos planteados en el cuestionario

\begin{tabular}{|l|c|}
\hline \multicolumn{1}{|c|}{ Núcleos planteados en el cuestionario } & $\begin{array}{c}\text { Número de preguntas que } \\
\text { contiene cada núcleo }\end{array}$ \\
\hline $\begin{array}{l}\text { Núcleo 0: } \\
\text { Caracterización de la población participante }\end{array}$ & 3 \\
\hline $\begin{array}{l}\text { Núcleo 1: } \\
\text { Formación para la enseñanza de las Ciencias Socia- } \\
\text { les }\end{array}$ & 4 \\
\hline $\begin{array}{l}\text { Núcleo 2: } \\
\text { Finalidades y contenidos del currículo de la ense- } \\
\text { ñanza de las Ciencias Sociales y, en concreto, del } \\
\text { conflicto social }\end{array}$ & 2 \\
\hline $\begin{array}{l}\text { Núcleo 3: } \\
\text { Metodologías, estrategias y recursos de enseñanza } \\
\text { yaprendizaje de las Ciencias Sociales }\end{array}$ & 3 \\
\hline $\begin{array}{l}\text { Núcleo 4: } \\
\text { Mapeo sobre la enseñanza del conflicto }\end{array}$ & 2 \\
\hline $\begin{array}{l}\text { Núcleo 5: Obstáculos para implementar la enseñanza } \\
\text { de las Ciencias Sociales y sus efectos en los aprendiza- } \\
\text { je del alumnado }\end{array}$ & 1 \\
\hline
\end{tabular}

Fuente: elaboración propia.

Se presentaron un conjunto de afirmaciones para ser escogidas por los docentes, asignando un valor de 1 a 5 , siendo 5 la opción a las que más apunta sus prácticas de enseñanza y 1 la de menos relevancia. Los resultados, al ser cruzados, permitieron identificar su pensamiento, relacionando aspectos como la utilidad de la enseñanza de las Ciencias Sociales.

Asimismo, los procesos relevantes para la enseñanza del conflicto, los tipos de competencias que se pretenden desarrollar y el enfoque curricular de práctica, en función de sus respuestas sobre las finalidades de los procesos de enseñanza y los tipos de metodologías, estrategias y recursos utilizados (Jiménez, 2015). La Tabla 3 compila lo que «piensan» los profesores sobre las prácticas de enseñanza de las Ciencias Sociales y, de manera particular, sobre el conflicto. 
Tabla 3. Pensamiento de los profesores sobra la enseñanza del conflicto

\begin{tabular}{|c|c|c|}
\hline $\begin{array}{l}\text { Utilidad de la enseñanza } \\
\text { de las Ciencias Sociales }\end{array}$ & \multicolumn{2}{|c|}{$\begin{array}{l}\text { Preparar a los alumnos para la vida adulta, siendo la his- } \\
\text { toria la base para entender los problemas sociales y para } \\
\text { promover el desarrollo de su espíritu crítico }\end{array}$} \\
\hline $\begin{array}{l}\text { Procesos curriculares } \\
\text { relevantes para la } \\
\text { ensefíanza del conflicto }\end{array}$ & \multicolumn{2}{|c|}{$\begin{array}{l}\text { Educación para la Paz } \\
\text { Resolución pacifica de los conflictos. } \\
\text { Pluralidad } \\
\text { Convivencia }\end{array}$} \\
\hline Tipos de competencias & \multicolumn{2}{|l|}{ Competencias ciudadanas } \\
\hline $\begin{array}{c}\text { Enfoque curricular al } \\
\text { que responde }\end{array}$ & $\begin{array}{l}\text { Enfoque práctico } \\
\text { Considera el desarrollo del cu- } \\
\text { rrículum sobre una base cua- } \\
\text { litativa, donde la explicación } \\
\text { y el diálogo emergen de cada } \\
\text { actividad de aprendizaje }\end{array}$ & $\begin{array}{l}\text { Enfoque curricular crítico } \\
\text { Está dirigido a la construcción } \\
\text { conjunta del conocimiento } \\
\text { entre los participantes acti- } \\
\text { vos del mismo a través de la } \\
\text { praxis, la fuente fundamental } \\
\text { para la selección de los con- } \\
\text { tenidos es la propia realidad } \\
\text { social en estrecho vínculo con } \\
\text { la comunidad donde se en- } \\
\text { cuentra ubicada la escuela. La } \\
\text { acción crítica es la praxis, que } \\
\text { se mueve entre la reflexión y } \\
\text { la acción. }\end{array}$ \\
\hline $\begin{array}{l}\text { Metodología que } \\
\text { responden al enfoque }\end{array}$ & \multicolumn{2}{|l|}{$\begin{array}{l}\text { Aprendizaje por Preguntas } \\
\text { Aprendizaje Cooperativo } \\
\text { Aprendizaje por Problemas } \\
\text { Aprendizaje por Competencias }\end{array}$} \\
\hline $\begin{array}{l}\text { Estrategias que } \\
\text { responden al enfoque }\end{array}$ & \multicolumn{2}{|c|}{$\begin{array}{l}\text { Interpretación de Imágenes } \\
\text { Formulación de hipótesis y lluvia de ideas } \\
\text { Análisis de situaciones cotidianas o hechos de contexto } \\
\text { Estudio de Caso }\end{array}$} \\
\hline $\begin{array}{l}\text { Recursos que } \\
\text { responden al } \\
\text { enfoque }\end{array}$ & \multicolumn{2}{|l|}{$\begin{array}{l}\text { Uso de las TIC } \\
\text { Uso de Videos } \\
\text { Unidades Didácticas } \\
\text { Mapas conceptuales } \\
\text { Lectura de noticias actuales }\end{array}$} \\
\hline
\end{tabular}

Fuente: elaboración propia.

Los resultados evidencian como el profesorado considera que la enseñanza de las Ciencias Sociales posee su utilidad en la preparación para la vida adulta, siendo la historia la base para entender los problemas sociales al fomentar el desarrollo del espíritu crítico. Para lograr este alcance es necesario reflexionar sobre los procesos curriculares relevantes como la Educación para la Paz, la resolución pacífica de los 
conflictos, la pluralidad y la convivencia. Desde ahí se infiere el mismo como constructo curricular y un problema objeto de estudios de las Ciencias Sociales.

En efecto, el trabajo consiste en generar una actitud que asuma tales confrontaciones como posibles escenarios de oportunidades y no como escenarios violentos. La educación para la paz conlleva valores, actitudes, comportamientos y modos de vida basados en la no-violencia y el respeto de los derechos y libertades fundamentales de cada persona. Sin duda, esto es lo que debe tener en cuenta el profesorado en el momento de argumentar la relevancia de educar para la vida adulta. Es así como tales actores plantean el valor de estos elementos curriculares en la educación, articulados a contenidos específicos de las Ciencias Sociales.

Esto responde a «la concepción que exige problematizar el contenido e invitar a los estudiantes a recorrer un proceso parecido al que realizan los historiadores y los científicos sociales» (Giroux, 2006, p. 83), para comprender que las Ciencias Sociales intentan explicar el significado de los conflictos, sus causas y sugerir vías para su solución.

Respecto a los tipos de competencia que deben desarrollar los estudiantes en la enseñanza de las Ciencias Sociales, están relacionadas con la reflexión ante su propio rol como docentes. Los estándares de competencias ciudadanas señalan que estas representan habilidades y conocimientos necesarios para construir convivencia, participar democráticamente y valorar el pluralismo; elementos que surgen en los resultados del cuestionario como proceso transversal necesarios en la enseñanza.

Al identificar las principales metodologías, estrategias y recursos usados el profesorado (analizados en la Tabla 2 de este artículo y ubicado en el cuestionario del Núcleo 3: metodologías, estrategias y recursos de enseñanza de las Ciencias Sociales) se puede deducir que su pensamiento sobre la representación social de las prácticas de enseñanza se enmarca en enfoques curriculares como el práctico y el crítico. Al parecer, para los profesores, la incorporación de metodologías y estrategias basadas en problemas, preguntas y experiencias de cooperación permite, en los niños y las niñas, acciones de pensamiento y de producción dentro de experiencias de aprendizaje basadas en el desarrollo de competencias para la interpretación, la argumentación, la proposición y las competencias ciudadanas.

\subsection{Fase código "in vivo»-axial - "¿Qué dice que hace el profesorado sobre la enseñanza del conflicto colombiano?»}

A partir del uso de las entrevistas, en esta fase la investigación se buscó compilar los argumentos expresados por los y las docentes en torno a las prácticas de enseñanza del conflicto, en el marco de las Ciencias Sociales, así como las representaciones sociales recopiladas en una entrevista a profundidad.

Posterior a la presentación de estos resultados por unidades de análisis y categorías más codificadas, se muestra el resultado de esta codificación abierta, a 
través de las categorías de mayor recurrencia en la entrevista al usar la teoría fundamentada (Glaser, 1992). Estas unidades han sido extraídas de manera inductiva como resultado de las expresiones que los y las docentes entrevistados manifestaron, vinculadas a las teorías conceptuales preconcebidas y que se perfilan como las categorías centrales (Tabla 4).

Tabla 4. Codificación selectiva sobre lo que dicen el profesorado

\begin{tabular}{|c|c|}
\hline \multicolumn{2}{|c|}{ Codigos sustantivos ablertos } \\
\hline $\begin{array}{l}\text { Decisiones didácticas para implementar la ense- } \\
\text { fanza del conflicto. }\end{array}$ & $\begin{array}{l}\text { La relación de los contenidos en Ciencias Socia } \\
\text { les para la ensefianza del conflicto: criterios para } \\
\text { su selección. }\end{array}$ \\
\hline $\begin{array}{l}\text { ¿Qué metodologlas y/o estrategias didácticas } \\
\text { usa para la ensef́anza de las Ciencias Sociales?, } \\
\text { podŕa explicar zcuál son los criterios de selec- } \\
\text { ción para su implementación? }\end{array}$ & $\begin{array}{l}\text { ¿Cuál es el criterio que utiliza el profesor para } \\
\text { seleccionar contenidos que aporten a la ense- } \\
\text { hanza del conflicto en el marco de las Ciencias } \\
\text { Sociales? }\end{array}$ \\
\hline \multicolumn{2}{|c|}{ Categorla más codificada } \\
\hline $\begin{array}{l}\text { Uso de estrategias como: el estudio de caso- } \\
\text { plasmada en unidades didácticas, el análisis de } \\
\text { problemas del contexto, la discusión dirigida, } \\
\text { las lecturas, las situaciones cotidianas, las expo- } \\
\text { siciones dirigidas por los estudiantes, la lluvia } \\
\text { de ideas sobre hipótesis posibles y las explica- } \\
\text { ciones del profesor. }\end{array}$ & $\begin{array}{l}\text { Contenidos históricos } \\
\text { - Los grupos sociales: familia, escuela y barrio } \\
\text { - El Bogotazo } \\
\text { - El Frente Nacional } \\
\text { - Origen de las guerrillas colombianas } \\
\text { - Violencia afnos } 80 \text { : El narcoterrorismo } \\
\text { - Origen del paramilitarismoy la extrema dere } \\
\text { cha en Colombia }\end{array}$ \\
\hline \multirow[t]{2}{*}{$\begin{array}{l}\text { Efecto de la ensefianza: Desarrollar el pensa- } \\
\text { miento crítico, el pensamiento creativo y crítico } \\
\text { a partir de la argumentación y la crítica }\end{array}$} & $\begin{array}{l}\text { Contenidos la Cátedra de la Paz } \\
\text { - Resolución pacifica de conflictos } \\
\text { - Justicia y Derechos Humanos } \\
\text { - Participación política } \\
\text { - Protección de las riquezas culturales y natura- } \\
\text { les de la Nación (Culturas indigenas) } \\
\text { - Diversidad y pluralidad } \\
\text { - Memoria histórica }\end{array}$ \\
\hline & $\begin{array}{l}\text { Contenidos la Cátedra en Democracia } \\
\text { - Mecanismos de Participación } \\
\text { - Derechos y deberes de los niflos } \\
\text { - Las Normas y su relación con la Convivencia }\end{array}$ \\
\hline \multicolumn{2}{|c|}{ Códigos teøricos } \\
\hline \multicolumn{2}{|l|}{ Las prácticas de ensefianza } \\
\hline \multicolumn{2}{|c|}{$\begin{array}{l}\text { Formar en prácticas de ensefianza a partir de la sinergia entre los contenidos, las competencias y } \\
\text { las estrategias de enseffanza como una decisión didáctica desde una postura crítica de su utilidad } \\
\text { y alcance. }\end{array}$} \\
\hline
\end{tabular}


Sobre los argumentos que el profesorado plantea sobre la importancia de enseñar el conflicto en la escuela, se relaciona con aspectos como la resolución pacífica de conflictos y la prevención del acoso escolar. Las decisiones didácticas para implementar la enseñanza del conflicto fue un aspecto indagado a través de la pregunta «¿cómo usa el maestro las problemáticas del contexto social como experiencias para la enseñanza-aprendizaje del conflicto?».

En este sentido, se identificó que enseñar tales enfrentamientos sociales enlistados por los profesores, en tanto problemáticas propias de sus contextos, puede estar relacionado con conceptos como víctimas, memoria y conflicto (Jiménez, 2020a), memoria histórica (Santisteban, 2010) y la historia de los acuerdos de paz, ubicados según los Estándares básicos en el currículum de Ciencias Sociales. Estas experiencias de enseñanza frente a tales confrontaciones de corte bélico asumen nuevos espacios en lo político, social, económico y cultural para el desarrollo de las competencias ciudadanas, entendidas como «el conjunto de conocimientos y de habilidades cognitivas, emocionales y comunicativas que, articulados entre sí, hacen posible que el ciudadano actúe de manera constructiva en la sociedad democrática» (Ministerio de Educación Nacional, 2006, p.8).

Al ahondar en los tipos de conflictos que más aquejan sus contextos los profesores lograron codificar solo las problemáticas, dejando de lado la descripción sobre las estrategias de enseñanza aprendizaje que usan para tal conectar la realidad social al currículo (Tabla 5).

Las codificaciones extraídas permiten analizar que, si bien el profesorado es consciente de las problemáticas sociales que existen en su entorno, se quedan cortos frente a la explicación sobre cómo usan estas problemáticas para la enseñanza del conflicto. De esta manera, se evidencia en las unidades extraídas para analizar

Tabla 5. Categorías más codificadas y menos codificadas sobre conflicto social

¿Cómo usa el maestro, las problemáticas del contexto social, como experiencias para la enseñanza-aprendizaje del conflicto?

Categorías que más codifica Conflicto Social

\section{Categorías que menos codifica} Conflicto de Género

Aprovecho las problemáticas de contexto: el suicidio, la pobreza, el desplazamiento, la reinserción del conflicto armado, el desplazamiento, la violencia intrafamiliar, el desempleo y la inseguridad.

Generando estrategias de enseñanza para abordar el conflicto del contexto y de la escuela. 
los correspondientes códigos, puesto que ningún profesor plantea las decisiones didácticas que toma para articular los tipos de conflicto enlistados a las estrategias de enseñanza. Esto es a partir de elementos como la preparación de clases o las metodologías a usar en sus prácticas.

\subsection{Fase Codificación selectiva - ¿Qué hace el profesorado? una radiografía a partir de la observación de la planificación y la implementación de las prácticas de enseñanza}

Para este momento de la investigación se recopilaron las propuestas didácticas y los materiales curriculares utilizados por el profesorado para la enseñanza del conflicto. Su intención fue analizar la coherencia entre la planeación de la clase, descifrando las decisiones didácticas que toman para la enseñanza del mismo, así como la implementación de métodos que operacionalicen parte de sus fines en la educación dentro del área. En este artículo se presentan dos de los resultados recolectados en la observación. El primero, la fase pre-activa: la programación encargada de describir el análisis sobre el plan de aula, las unidades didácticas, los libros reglamentarios (estándares y lineamientos curriculares en Ciencias Sociales).

Respecto a la etapa activa, la misma buscó describir lo sucedido en la clase, basados en el actuar del profesorado, recopilado en una lista de chequeo y comparando lo que estaba programado frente a lo que sucedió realmente en todos los aspectos (propósitos, objetivos, contenidos, métodos etc.). Cierra este apartado, la interpretación de esta situación con los resultados de las entrevistas.

En la Tabla 6 se compilaron los resultados de la fase pre-activa, donde se logró contrastar si en estas planeaciones el profesorado declaró los propósitos o las finalidades de la enseñanza del conflicto, sus objetivos de aprendizaje, las competencias a desarrollar, los contenidos programados sobre el tema que desea abordar y su secuencia (unidad didáctica). También, fueron rastreadas las actividades de enseñanza y de aprendizaje, la racionalidad de los métodos y los materiales que utiliza el docente y el alumnado.

Los resultados permiten afirmar que un gran número de profesores siguen optando por usar el libro de texto, como un referente básico en el desarrollo de su práctica profesional. Al parecer este dispositivo de enseñanza está algo extendido y aferrado a las prácticas de enseñanza del profesorado colombiano. Sin duda, el libro de texto establece una zona de confort para no construir las unidades didácticas, sin advertir la cantidad de decisiones que podría/debería haber tomado el docente al dimensionar lo que significa la planeación; no como una exigencia administrativa, por el contrario, como un proceso de toma de decisiones sobre los diferentes elementos que componen el currículo escolar. 
Tabla 6. Contrastación de los materiales para la enseñanza del conflicto

\begin{tabular}{|c|c|c|c|c|c|c|}
\hline $\begin{array}{l}\text { Tipo de } \\
\text { material }\end{array}$ & $\begin{array}{l}\text { Aspectos observados en } \\
\text { los materiales por caso }\end{array}$ & Caso 1 & Caso 2 & Caso 3 & Caso 4 & Caso 5 \\
\hline \multirow{3}{*}{ 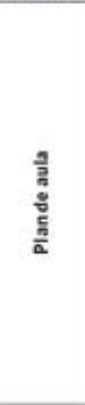 } & $\begin{array}{l}\text { Propositos o las } \\
\text { finalidades sobre la } \\
\text { ensefanza } \\
\text { del conflicto }\end{array}$ & $\begin{array}{l}\text { La contiene } \\
\text { sustentada en los } \\
\text { estandares }\end{array}$ & $\begin{array}{c}\text { Presenta mapa } \\
\text { mental } \\
\text { La contiene } \\
\text { sustentado en } \\
\text { los estandares, } \\
\text { lineamient os y DBA }\end{array}$ & $\begin{array}{l}\text { Presenta } \\
\text { flujograrna } \\
\text { Nodeclara }\end{array}$ & No declara & Nodeclara \\
\hline & $\begin{array}{c}\text { Objetivos de aprendizaje o } \\
\text { competencias a desarrollar } \\
\text { por el estudiante }\end{array}$ & $\begin{array}{l}\text { Contiene } \\
\text { competencias }\end{array}$ & $\begin{array}{l}\text { Contiene objetivos } \\
\text { y una competencia } \\
\text { de orden cognitivo } \\
\end{array}$ & $\begin{array}{l}\text { Contiene un } \\
\text { objet ivo }\end{array}$ & $\begin{array}{l}\text { Contiene } \\
\text { competencias }\end{array}$ & No declara \\
\hline & $\begin{array}{c}\text { Contenidos programados } \\
\text { (enseflanza de conflict o) y } \\
\text { su secuencia u orden en la } \\
\text { unidad didáctica }\end{array}$ & $\begin{array}{c}\text { Contiene temas } \\
\text { como: El Bogotazo, } \\
\text { frentenacional, } \\
\text { séptima papeletay } \\
\text { diallogos de paz. }\end{array}$ & $\begin{array}{l}\text { Contiene temas } \\
\text { como: Convivencia } \\
\text { pacificay defensa } \\
\text { y promoción de los } \\
\text { derechos humanos. }\end{array}$ & $\begin{array}{c}\text { Contiene temas } \\
\text { como:Derechos } \\
\text { humanos, las } \\
\text { comunidades, } \\
\text { la constitución } \\
\text { politica y la } \\
\text { democracia. }\end{array}$ & $\begin{array}{c}\text { Contiene temas } \\
\text { como: convivencia } \\
\text { y paz, participación } \\
\text { y responsabilidad } \\
\text { democrática y plu- } \\
\text { ralidad, identidad } \\
\text { y valoración de las } \\
\text { diferencias. }\end{array}$ & $\begin{array}{c}\text { Contiene temas } \\
\text { como migracion y la } \\
\text { inmigración en los } \\
\text { contextos rurales y } \\
\text { urbanos. }\end{array}$ \\
\hline \multirow{3}{*}{ 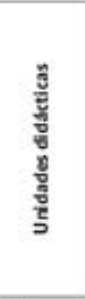 } & $\begin{array}{l}\text { Las actividades de ense } \\
\text { Aanza y de aprendizaje } \\
\text { qué está previsto que haga } \\
\text { el alumnado yel docente }\end{array}$ & La contiene & $\begin{array}{l}\text { De orden } \\
\text { conceptual }\end{array}$ & No presento & \multirow{3}{*}{$\begin{array}{l}\text { Sustituida por el } \\
\text { libro texto }\end{array}$} & No present $\delta$ \\
\hline & $\begin{array}{c}\text { La racionalidad } \\
\text { de los métodos y } \\
\text { estrategias usados } \\
\text { para operacionatizar } \\
\text { los propositos de la } \\
\text { enseflanza }\end{array}$ & $\begin{array}{l}\text { La contiene } \\
\text { "estudio decaso" }\end{array}$ & $\begin{array}{l}\text { La contiene } \\
\text { "estudio de caso" }\end{array}$ & No present $\delta$ & & No presento \\
\hline & $\begin{array}{l}\text { Los materiales que utiliza } \\
\text { el docente y el alumnado }\end{array}$ & La contiene & La contiene & No present $\delta$ & & No presentó \\
\hline \multirow{8}{*}{ 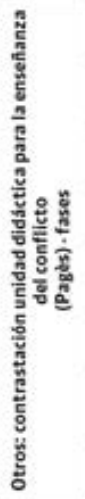 } & $\begin{array}{l}\text { 1. Descripción general del } \\
\text { conflicto }\end{array}$ & \multirow{8}{*}{$\begin{array}{c}\text { Implementa todas } \\
\text { las fases }\end{array}$} & \multirow{8}{*}{ Solo usa la fase 1} & \multirow{8}{*}{$\begin{array}{l}\text { Solo usa la fase } 1 \\
\text { declarada en el plan } \\
\text { de aula a modo de } \\
\text { flujograma }\end{array}$} & \multirow{8}{*}{$\begin{array}{l}\text { No se pudo identifi- } \\
\text { car, pues no existe } \\
\text { unidad didactica }\end{array}$} & \multirow{8}{*}{$\begin{array}{l}\text { No se pudo identifi- } \\
\text { car, pues no existe } \\
\text { unidad didactica }\end{array}$} \\
\hline & $\begin{array}{l}\text { 2. Historia antecedentes } \\
\text { del conflicto }\end{array}$ & & & & & \\
\hline & 3. Contexto del conflicto & & & & & \\
\hline & $\begin{array}{l}\text { 4. Partes implicadaso } \\
\text { protagonistas }\end{array}$ & & & & & \\
\hline & 5. Problemas en juego & & & & & \\
\hline & $\begin{array}{l}\text { 6. Dinamicas } \\
\text { desarrolladas }\end{array}$ & & & & & \\
\hline & $\begin{array}{l}\text { 7. Al ternativas para } \\
\text { solucionar el problema }\end{array}$ & & & & & \\
\hline & $\begin{array}{l}\text { 8. Regulación potencial } \\
\text { del conflicto }\end{array}$ & & & & & \\
\hline
\end{tabular}

Fuente: elaboración propia.

Los casos 3, 4 y 5 plantean la enseñanza del conflicto a partir de los contenidos programáticos aislados de la realidad, entendiendo «la historia como el estudio del pasado». En el caso 2, "los que tratan de las causas y de las consecuencias de los hechos, en este caso del Holocausto, ponen el énfasis en el saber, pero descuidan otros objetivos de la enseñanza de la historia». Solo el caso 1 se acerca al profesor sociocrítico, aquel que encausa sus prácticas y "relacionan el pasado con el presente, que presentan el holocausto como un hecho pasado, pero estudian de qué manera influye todavía en nuestras vidas». 
En la fase activa, observación y descripción del desarrollo de cada clase, se creó la lista de chequeo que integra los tipos de métodos de enseñanza, separada en dos columnas, cada una de ella posee ítems a marcar con una X, dado el caso que se identificaran dinámicas de aula que apuntaran a un método individual interactivo o expositivo. Este instrumento surge a partir de las posturas de Quinquer (1997) y la descripción específica de cada método. Frente a la manera como se extrajeron los resultados fue desde la cantidad de dinámicas de aula implementadas por método. Estas serán la suma, por columna, de cada uno y prevalecerá el de mayor valor (Tabla 7).

Tabla 7. Lista de chequeo sobre tipos de prácticas de enseñanza

\begin{tabular}{|c|c|c|c|}
\hline \multicolumn{4}{|c|}{$\begin{array}{l}\text { RISARALDAPEREIRA } \\
\text { ZONA RURAL } \\
\text { Lic. en Tecnologia Educativa }\end{array}$} \\
\hline \multicolumn{4}{|c|}{$\begin{array}{l}\text { Tipos de métodos de enseflanza implementados } \\
\text { OBJETIVO: Identificar los tipos de métodos para la enseflanza del Conflicto } \\
\text { que Implementa el profesorado de básica primaria }\end{array}$} \\
\hline \multicolumn{2}{|c|}{$\begin{array}{l}\text { Dinámica de aula del estudiante y el profe } \\
\text { sor en el Método Expositivo }\end{array}$} & \multicolumn{2}{|c|}{$\begin{array}{l}\text { Dinámica de aula del estudiantey el pro- } \\
\text { fesor en el métodos Método Interactivo }\end{array}$} \\
\hline Se sientay escucha & $\mathrm{X}$ & Se muevey experimenta & \\
\hline $\begin{array}{l}\text { El aprendiz es un receptor del cono- } \\
\text { cimlento }\end{array}$ & $\mathrm{x}$ & $\begin{array}{l}\text { El aprendiz es un Iniclador del } \\
\text { proceso }\end{array}$ & \\
\hline Se espera lo mismo de cada uno & & $\begin{array}{l}\text { Cada uno posee saberes previos } \\
\text { y es particular }\end{array}$ & $\mathrm{x}$ \\
\hline El aprendiz aje se orlenta al producto & $\mathrm{x}$ & $\begin{array}{l}\text { El estudlante orienta el proceso } \\
\text { y el producto }\end{array}$ & \\
\hline $\begin{array}{l}\text { El profesor"dice } \cos ^{*} \text { " y el estudian- } \\
\text { te no replica }\end{array}$ & & $\begin{array}{l}\text { El estudlante construye signifi- } \\
\text { cados de lo aprendldo }\end{array}$ & $\mathrm{x}$ \\
\hline $\begin{array}{l}\text { La interacción con el conocimiento es } \\
\text { basada en el papel y el láplz. }\end{array}$ & $\mathrm{x}$ & $\begin{array}{l}\text { Enriquecido por la tecnologia y } \\
\text { el contexto }\end{array}$ & \\
\hline $\begin{array}{l}\text { El libro texto es la herramlenta didac- } \\
\text { tica por excelencla }\end{array}$ & $\mathrm{x}$ & $\begin{array}{l}\text { Las Unidades Didácticas articu- } \\
\text { ladas a experienclas de contex- } \\
\text { to y uso de TiC permiten apren- } \\
\text { der en contexto. }\end{array}$ & $x$ SIN \\
\hline $\begin{array}{l}\text { Se brindan Indicaciones explicitas } \\
\text { que se acogen si preguntar }\end{array}$ & $\mathrm{x}$ & Dı́logo de saberes y preguntas & $\mathrm{x}$ \\
\hline Sumiso & $\mathrm{X}$ & Soluciona problemas & \\
\hline $\begin{array}{l}\text { Las respuestas son lo principal en el } \\
\text { aprendizaje }\end{array}$ & $\mathrm{x}$ & $\begin{array}{l}\text { Las preguntas son } 10 \text { principal } \\
\text { en el aprendizaje }\end{array}$ & \\
\hline SIstema cerrado al contexto & $\mathrm{x}$ & SIstema ablerto al contexto & \\
\hline $\begin{array}{l}\text { La ubicacion del aula permanecen } \\
\text { slempreigual }\end{array}$ & $\mathrm{x}$ & $\begin{array}{l}\text { La ubicación en el aula cambla } \\
\text { constantemente privilegiando } \\
\text { el trabajo en equipo }\end{array}$ & \\
\hline Saben hechos, datos, fechas & & Hace preguntas & $\mathrm{x}$ \\
\hline $\begin{array}{l}\text { Hay un modo correcto de hacer las co- } \\
\text { sas: como las ensena el profesor }\end{array}$ & $\mathrm{x}$ & $\begin{array}{l}\text { Hay múltiples modos de solucio- } \\
\text { narlo }\end{array}$ & \\
\hline
\end{tabular}

Fuente: elaboración propia. 
A partir de ahí fue posible observar una fragmentación sobre las prácticas de enseñanza que implementa el profesor dejando de lado los fines, objetivos, metodologías y competencias a los que podrían apuntar estos procesos. De igual manera, el desarrollo del pensamiento crítico, dado que no existe una metodología que posibilite técnicas de enseñanza grupales en el marco de las dinámicas sociales.

En la práctica observada, prevalecen las dinámicas inductivas y se dejan de lado los métodos y las técnicas de enseñanza de corte interactivo. Según Quinquer (1997), este tipo de técnicas permiten el intercambio de puntos de vista, la participación abierta y flexible, la cooperación y la construcción colectiva de conocimientos. Esto se pudo recolectar al observar las clases de los profesores participantes en la investigación utilizando para ello una lista de chequeo con ítems extraídos de las teorías.

Generalmente, la mayoría de los docentes acude al método expositivo como protagonista del proceso educativo, cuyo objetivo central es la comunicación de conocimientos para el aprendizaje desde emisiones verbales y las posturas pasivas de recepción en los estudiantes. En los métodos expositivos predomina la voz del docente quien conduce el sentido de la información y la pone al servicio de su propia argumentación. El aprendizaje que tiende a privilegiarse en este método es auditivo y memorístico, desde la imagen arquetípica del maestro que impone el poder con su conocimiento.

En las diferentes propuestas de adaptación o aplicación de los planteamientos de la teoría crítica al mundo de la educación, es necesario que el profesorado identifique que, más allá del uso de técnicas de enseñanza, para el desarrollo del pensamiento crítico debe enfocarse en el diseño de un currículo que aborde los problemas sociales, la deliberación, las relaciones horizontales entre las personas que forman parte de la institución educativa (Giroux, 2006; Young, 1993). Desde estos resultados, se encuentra que solo dos de los cinco profesores observados expresan la importancia de articular los problemas sociales como base para la enseñanza del conflicto.

\section{DISCUSIÓN}

4.1. ¿Cuáles son los aportes y las conclusiones de esta investigación sobre la enseñanza del conflicto colombiano en los maestros de Ciencias Sociales?

La representación social del profesorado de Básica Primaria sobre la enseñanza del conflicto colombiano constituye un aspecto clave que se ha tenido en cuenta en el marco de esta investigación. A partir de esta intención, se buscó descifrar dicha representación desde lo revelado en la recolección de datos emergentes. Posterior al análisis, se presenta en la Figura 2 sobre la configuración de 
Figura 2. Codificación teórica sobre la enseñanza del conflicto colombiano: triangulación de instrumentos

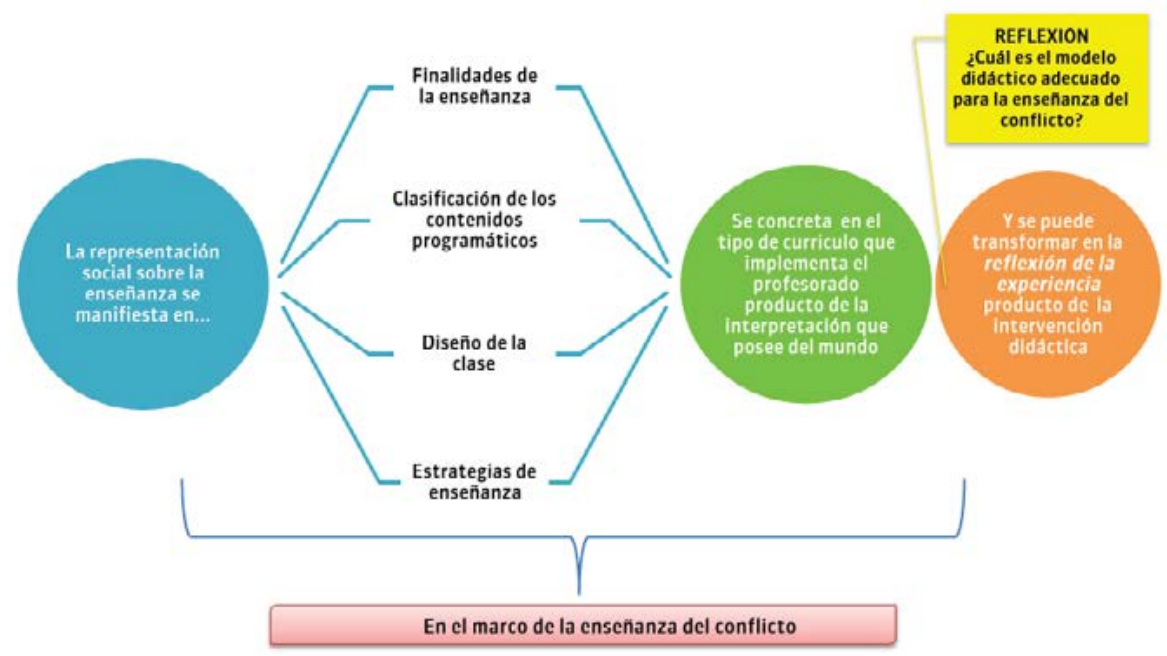

Fuente: elaboración propia.

los códigos teóricos, mediante el modelo de análisis aplicado desde la teoría fundamentada. Los resultados de la codificación hicieron parte de la discusión de la tesis doctoral que dio origen al presente artículo.

La figura presenta las codificaciones sobre la enseñanza del conflicto colombiano que se han extraído de los datos obtenidos, fase a fase para identificar dichas representaciones. La representación social del profesorado concreta aspectos propios de la didáctica de las Ciencias Sociales, como la finalidad de la enseñanza del conflicto y la clasificación de los contenidos programáticos elegidos por los docentes. Estos aspectos se conectan con las problemáticas de contexto y las decisiones didácticas que implementan para la preparación o diseño de la clase y, también, al momento de plantear estrategias de enseñanza.

El análisis de estos elementos permite descifrar el tipo de currículo y, por ende, la finalidad de la enseñanza del conflicto en el que se enmarca el profesorado, a partir de las posturas de Moscovici (1998), donde se define que «en el estudio, del cómo y del porqué la gente comparte conocimiento y construye su realidad común, de cómo ellos transforman ideas en prácticas - un mundo del poder de las ideases un problema específico de la psicología social» (Moscovici, 1998, p. 2). Así, el acto de representación hace parte del pensamiento y, por medio de este, el sujeto se relaciona y comprende los objetos que hacen parte de su contexto.

Al hablar de las representaciones es importante reconocer dos procesos fundamentales: objetivación y el anclaje. El primero expresa el elemento social de las 
representaciones, es decir, la materialización de significados como formas visibles y atribuibles a las personas. como un modo de conocer. Esto permite afirmar que la representación social del conflicto tiende a una objetivación producto, únicamente, de la percepción del contexto y su experiencia derivada de un saber cultural, sin ningún tipo de rigor científico que surja, ya sea de su formación en la Licenciatura en Ciencias Sociales o de la solvencia frente al manejo y conceptualización del pensamiento histórico.

En cuanto al anclaje sobre el valor que tiene la enseñanza del conflicto colombiano para el profesorado es representada desde la percepción de los conflictos inmersos en su contexto y que enmarcan su realidad, sea local o nacional. De este modo, los docentes afirman que, en medio del debate sobre lo que la escuela debe asumir y reflexionar, el interés está relacionado con el conflicto escolar, conflicto cotidiano y conflicto social. La Figura 5 resume el mapeo extraído de esta investigación sobre las representaciones sociales que posee el profesorado para enseñar conflicto social.

Figura 3. Representación social sobre el conflicto colombiano en el profesorado

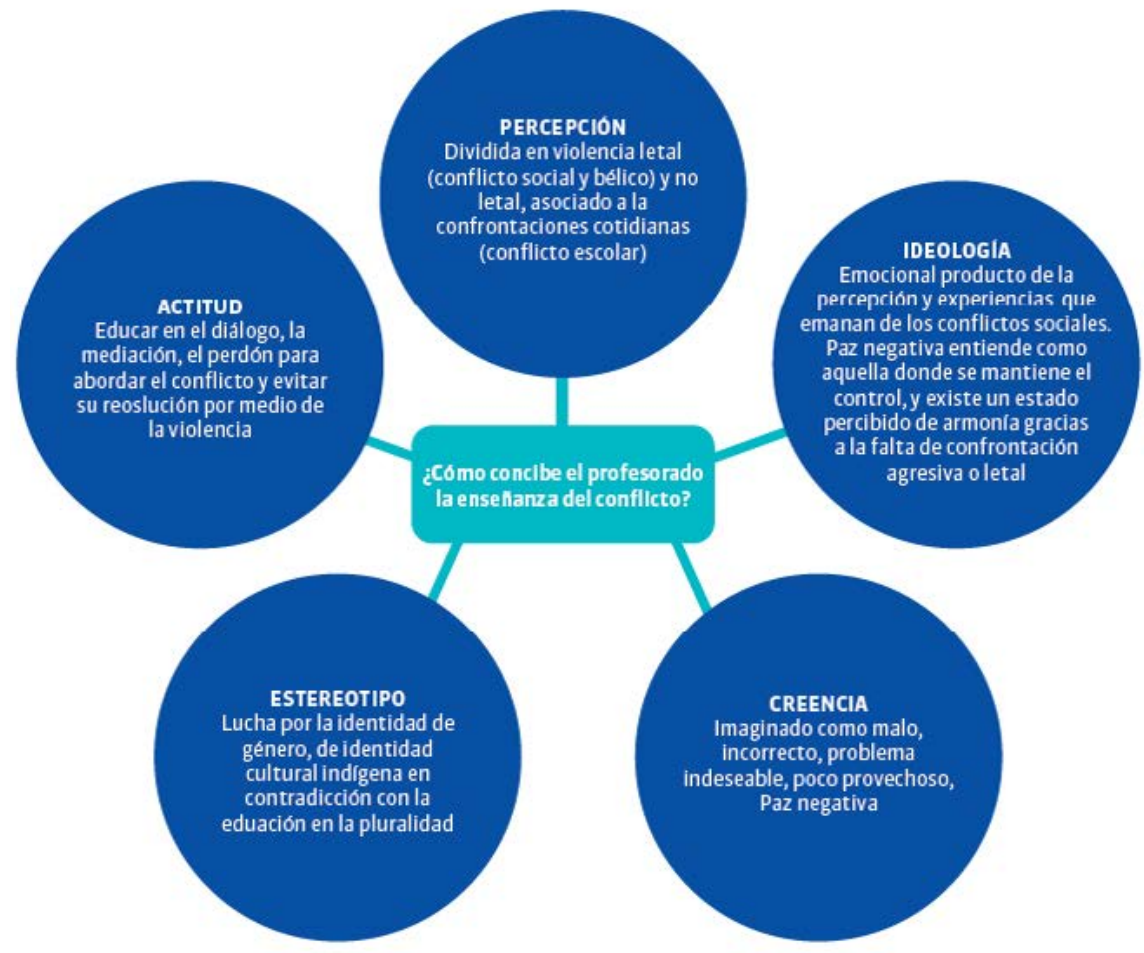

Fuente: elaboración propia. 
Este resultado sostiene algunas de las posturas de Moscovici (1985), centrado en que la mayoría de las personas acuden a esos saberes de la cultura, a las creencias y a aquellos conocimientos de sentido común. Estos saberes coexisten con las explicaciones científicas difundidas por la escuela, los medios de comunicación y las conversaciones formales o informales para explicar ciertos hechos que constituyen el escenario cotidiano de los agentes sociales.

Finalmente, sobre las prácticas para la enseñanza del conflicto, los resultados se respaldan en las posturas de Bruner (1997), quien señala las dificultades que se presentan para reconocer su nicho didáctico, así como su implementación a partir del mundo de la opinión, la argumentación y la explicación de este fenómeno mediante el conocimiento informal. Entre tanto, hace énfasis en los errores que puede presentar el profesorado cuando promueve prácticas de su enseñanza exclusivamente informales, haciendo un llamado para que incluya en sus prácticas un pensamiento científico fundamentado en hechos históricos.

Esta afirmación se sustenta en la escasa construcción de las unidades didácticas para la enseñanza del conflicto. No se encontraron evidencias sobre la articulación de los tipos de contenido, competencias, estrategias didácticas, finalidades de la enseñanza y metodologías que permiten experimentar el alcance de un enfoque curricular clasificado por Pagès (1994) como técnico, práctico o emancipatorio. Por esta razón,

las representaciones sociales de objetivación de la enseñanza de este son resultado de un saber incipiente e informal en el profesorado que omite la reflexión sobre su enseñanza en la escuela.

Esta tendencia ha repercutido en la manera cómo actúan los ciudadanos de hoy y en la configuración de una cultura colombiana con largos lastres de violencia basada, en patrones de relaciones que conducen a romper más los lazos sociales y morales. En la Figura 4 se exponen las formas de enseñanza más relevantes del profesorado colombiano.

En consecuencia, se evidencia gran debilidad de las estrategias de enseñanza del conflicto a través de la ausencia de las unidades didácticas que dejan de construir los profesores, delegando el saber científico de su construcción a los editores de los libros que las sustituyen en el aula. De manera alterna, se observa una fractura entre los contenidos curriculares que no permite al estudiante reestructurar su imagen del mundo y reconocer las problemáticas de su contexto. Entonces, es posible inferir que el profesor no considera la historia como una herramienta de análisis y aprendizaje, situando el ejercicio pedagógico en el plano de la empatía y la contextualización (Santisteban, 2009).

De esta manera, se hace necesario socavar diferentes modelos didácticos y procesos de enseñanza a favor de la conciencia histórica y temporal, configurada desde las relaciones establecidas entre sus respectivas categorías: pasado, presente y futuro (Tutiaux-Guillon, 2003; Pagès, 2003; Santisteban y Pagès, 2008). En defini- 
Figura 4. Prácticas de enseñanza más relevantes del profesorado colombiano

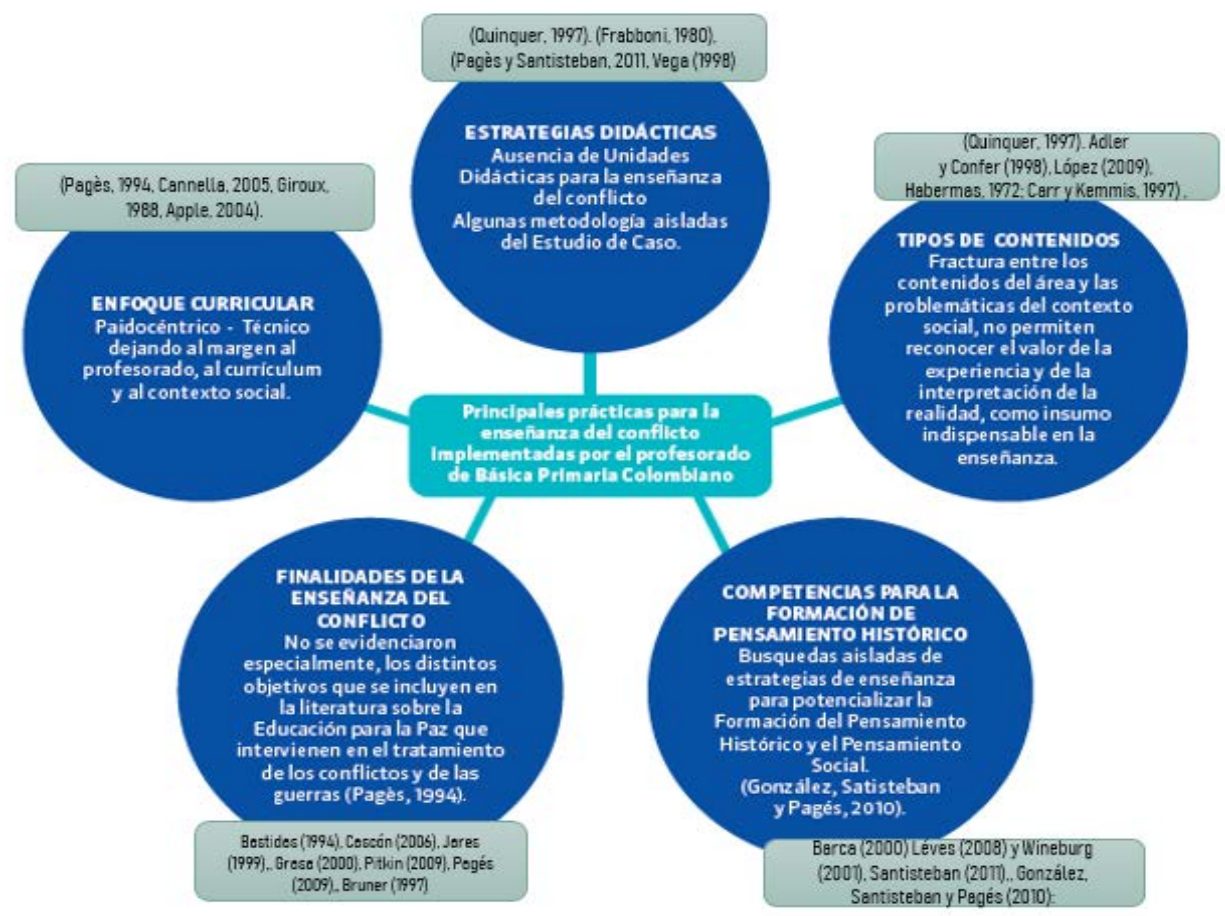

Fuente: elaboración propia.

tiva, el asunto está en permitirle al individuo aprender experiencias que lo lleven a ser un ciudadano capaz de tomar decisiones crítico-creativas, centradas en competencias como la empatía social y transformación de problemáticas de contexto.

Una alternativa posible que permita identificar caminos para la formación en la enseñanza del conflicto es reconocer la propuesta de unidad didáctica hecha por Pagès (1997), donde se incorpora el modelo de estudio de conflictos desarrollado desde la Educación para la Paz propuesto por Wehr (citado por Fisas, 2005). A partir de ahí, Grasa (1991) propone una guía cartográfica que considera los siguientes elementos: descripción general del conflicto, historia o antecedentes, contexto, partes implicadas o protagonistas, problemas en juego, dinámicas desarrolladas, alternativas para solucionar el problema y regulación potencial del mismo. 


\section{REFERENCIAS BIBLIOGRÁFICAS}

Abric, J. (2001). Metodología de recolección de las representaciones sociales. En

J. C. Abric (coord.), Prácticas sociales y representaciones (pp. 53-74). México: Ediciones Coyoacán.

Adler, S. (2008). The education of social studies teacher. En S. Levstik \& A. Tyson (eds.), Handbook of research in social studies education (pp. 329-350). New York: Taylor and Francis.

Adler, S. \& Goodman, J. (1983). What is social studies? Student teacher perspectives. Presentation to the National Council for the Social Studies (San Francisco, CA). Recuperado el 20 de abril de 2020 de https://eric.ed.gov/?id=ED240033

Angrosino, M. (2012). Etnografía y observación participante en investigación cualitativa. Madrid: Ediciones Morata.

Audigier, F. (2002). Un estudio sobre la enseñanza de la historia, la geografía y la educación cívica en la escuela elemental en Francia: temas, métodos y preguntas. Revista Enseñanza de las Ciencias Sociales, 1, pp. 3-16.

Avery, P. (2010). Investigación sobre la enseñanza de las ciencias sociales y la educación del profesor. En R. Ávila y P. Domínguez, Metodología en investigación en didácticas de las Ciencias Sociales (pp. 337-355). Zaragoza: Institución Fernando El Católico.

Dukes, F. (1999). Structural Forces in Conflict and Conflict Resolution in Democratic Society. En H. Won Jeong (ed.), Conflict Resolution: Dynamics, Process and Structure (pp. 155-172). Brookfield: Ashgate. https://doi. org/10.4324/9780429444142-7

Bravo, L. (2002). La formación inicial del profesorado de secundaria en didácticas de las ciencias sociales en la Universidad Autónoma de Barcelona: un estudio de caso (tesis de doctorado). Barcelona: Universidad Autónoma de Barcelona.

Capella, J. (2004). Políticas educativas. Educación, 13(25), pp. 7-41. http://revistas. pucp.edu.pe/index.php/educacion/article/view/10565

Carr, W. y Kemmis, S. (1997). Teoría crítica de la enseñanza. La investigación-acción en la formación del profesorado. Barcelona: Martínez Roca. 
Coser, L. (1972). The Functions of Social Conflict. New York: Free Press.

Calderón, P. (2009). Teoría de conflictos de Johan Galtung. Revista Paz y Conflictos, 2, pp. 60-81.

Denzin, N., y Lincoln, Y. (2012). Manual de investigación cualitativa. El campo de la investigación cualitativa. Barcelona: Gedisa.

Evans, M. (2006). Characterizations of citizenship education pedagogy in Canada and international of citizenship. Teaching and Learning, 2(4), pp. 40-54.

Evans, R. W. (1994): Educational Ideologies and the Teaching of History. En G. Leinhardt, I. L. Beck y C. Stainton (eds.), Teaching and learning in History (pp. 171-207). Hillsdale, New Jersey: Lawrence Erlbaum Associates.

Fisas, V. (1987). Introducció a l'estudi de la pau i dels conflictes. Barcelona. Fundación Jaume.

Fisas V. (2005) Abordar el Conflicto: la negociación y la mediación. Revista Futuros, 10(3). http://www.revistafuturos. http://www.uninorte.edu.co/web/dialogosde-paz-en-la-habana-y/entradas-de-blog/-/blogs/abordar-el-conflicto:-lanegociacion-y-la-mediacion-

Galtung, J. (2003). Trascender y transformar. Una introducción al trabajo de conflictos. México: Quimera.

González, G. (2012). La formación inicial del profesorado de Ciencias Sociales y la Educación para la Ciudadanía en Colombia: representaciones sociales y prácticas de enseñanza (tesis de doctorado). Barcelona: Universidad Autónoma de Barcelona.

Giroux, H. (2006). La escuela y la lucha por la ciudadanía: pedagogía crítica de la época. Ciudad de México: Siglo XXI.

Glaser, B. G. (1992). Basics of grounded theory analysis. California: Sociology Press.

Jara, M. (2010). Representaciones y enseñanza de la historia reciente-presente. Estudio de casos de estudiantes en formación inicial y en su primer año de docencia (tesis de doctorado). Barcelona: Universidad Autónoma de Barcelona. 
Jiménez-Becerra, I. (2015). Pedagogía de la creatividad viable: un camino para potencializar el pensamiento crítico. Opción, 31(2), pp. 632-653. https://www. redalyc.org/pdf/310/31045568035.pdf

Jiménez, I. (2018). Representación Social del Conflicto Colombiano en Profesores de Básica Primaria (tesis de doctorado). Barcelona: Universidad Autónoma de Barcelona.

Jiménez, I. (2020) El Triángulo Lógico: Una ecuación didáctica emergente para aprender metodología de la investigación. Chía: Universidad de La Sabana.

Jiménez, I. (2020). Modelo didáctico tecnosocial: una experiencia de educación para la ciudadanía con jóvenes universitarios desde el estudio de los conflictos sociales. El Futuro del Pasado, 11, pp. 637-658. https://doi.org/10.14516/ fdp.2020.011.021.

Jiménez, I.; Segovia, Y. (2020) Modelos de integración didáctica con mediación TIC: algunos retos de innovación en las prácticas de enseñanza. Culture and Education, 32(3), pp. 399-440. https://doi.org/10.1080/11356405.2020.17851 40

Jodelet, D. (2013). La representación social: Fenómenos, Conceptos y Teoría. En S. Moscovici (ed.), Psicología Social II (pp. 469-494). Barcelona: Paidós.

Krause, M. (2003). The Transformation of Social Representations of Chronic Disease in a Self-Help Group. Journal of Health Psychology, 8(5), pp. 599-615. https:// doi.org/10.1177/13591053030085010

Lederach, J. (2007). La Imaginación moral. El arte y alma de la construcción de paz. Bilbao: Bakeaz

Lewin, K. (1988). Acción-investigación y problemas de las minorías. Revista de Psicología Social, 3(2), pp. 229-240. https://doi.org/10.1080/02134748.1988. 10821586

Llobet, V. (2005). La promoción de resiliencia con niños y adolescentes. Entre la vulnerabilidad y la exclusión. Buenos Aires: Novedades Educativas

Mitchell, J. (1969). The Concept and Use of Social Networks. En J. Mitchell (ed.), Social networks in urban situations (pp. 1-50). Manchester: Manchester University Press. 
Ministerio de Educación Nacional de Colombia. (2006). Estándares Básicos de Competencias en lenguaje, matemáticas, ciencias y ciudadanía. Bogotá: Imprenta Nacional de Colombia.

Moscovici, S. (1985). Psicología social I: influencia y cambios de actitudes, individuos y grupos. Barcelona: Paidós.

Moscovici, S. (1998). The history and actuality of social representations. En U. Flick (ed.), The Psychology of the Social (pp. 209-247). Cambridge: Cambridge University Press.

Pagès, J. (1997). Los conflictos en las sociedades rurales: el conflicto Remensa (s. XV) y el conflicto de Chiapas (1994). En P. Benejam y J, Pagés, Ciencias sociales, contenidos, actividades y recursos (pp. 415-480). Barcelona: Praxis.

Pagés, J. (2002). Aprender a enseñar historia y ciencias sociales: el currículo y la didáctica de las Ciencias Sociales. Revista Pensamiento Educativo, 30, pp. 255269.

Pagés, J., y Oller, M. (2007). Las representaciones sociales del derecho, la justicia y la ley de un grupo de adolescentes catalanes de 4을 de ESO. Enseñanza De Las Ciencias Sociales, 6, pp. 3-19.

Quinquer, D. (2002). Estrategias de enseñanza: los métodos interactivos. En P. Benejam y J. Pagès, (coords.), Enseñar y aprender ciencias sociales, geografía e historia en la educación secundaria (pp. 97-122). Barcelona: Horsori.

Redorta, J. (2004). Cómo analizar los conflictos. la tipología de conflictos como herramienta de mediación. Barcelona: Paidós.

Rodríguez, T. (2007). Sobre el estudio cualitativo de la estructura de las representaciones sociales. En T. Rodríguez y M. García (Coords.), Representaciones sociales. Teoría e investigación. (pp. 157-190). Guadalajara: Editorial CUCSH-UdeG.

Rodríguez, A. (2016). La educación y la construcción de paz. Magisterio. https:// www.magisterio.com.co/articulo/la-educacion-y-la-construccion-de-la-paz

Ross, E. W. (2006). The social studies curriculum. New York: SUNY Press. 
Salinas, M., e Isaza, L. (2003). Para educar en el valor de la justicia. Representaciones sociales en el marco de la escuela. Bogotá: Editorial Magisterio.

Santisteban, A. (2005). Les representacins i l'ensenyament del temps históric. Estudis de cas en formació incial de mestres de primária en didáctica de les Ciéncies Socials (tesis de doctorado). Barcelona: Univeritat Autónoma de Barcelona.

Santisteban, A. (2009). Cómo trabajar en la clase la competencia social y ciudadana. Aula de Innovación Educativa, 187, pp.12-15.

Santisteban, A. y Pagès, J. (2007). La educación democrática de la ciudadanía: una propuesta conceptual. En R. Ávila, R. López, R. y E. Fernández (eds.), Las competencias profesionales para la enseñanza y aprendizaje de las ciencias sociales ante el reto europeo y la globalización (pp. 353-367). Bilbao: AUPDCS.

Schellenberg, J. (1982). The science of conflict. Oxford: Oxford University Press.

Shaver, J. (2001). La epistemología y la educación de los docentes de las Ciencias Sociales. En E. Arrondo, La formación docente en el profesorado de historia: ámbito en conflicto (pp. 41-61). Rosario, Argentina: Homo Sapiens.

Strauss, A. L. y Corbin, J. (2002). Bases de la investigación cualitativa: técnicas y procedimientos para desarrollar la teoría fundada. Medellín: Editorial Universidad de Antioquia.

Taylor, S. y Bogdan, R. (1992). Introducción a los métodos cualitativos en investigación. La búsqueda de los significados. Ciudad de México: Paidós.

Tutiaux-Guillon, N. (2003). Los fundamentos de una investigación sobre la concepción de las finalidades cívicas y culturales del profesorado de geografía e historia: objetivo de esta etapa. Enseñanza de las ciencias sociales: revista de investigación, 2, pp. 27-36.

Virta, A. (2002). Becoming a history teacher: observations on the beliefs and growth of student teachers. Teaching \& teacher education: an international journal of research and studies, 18(6), pp. 687-698. https://doi.org/10.1016/S0742051X(02)00028-8

Virta, A. (2009). Learning to teach history in culturally diverse classrooms. Intercultural Education, 20(4), pp. 285-297. https://doi.org/10.1080/14675980903351920 
Thornberg, R. (2010). Schoolchildren's social representations on bullying causes. Psychology in the Schools, 47(4), pp. 311-327. https://doi.org/10.1002/ pits.20472

Vinyamata, E. (2001). Conflictología. Barcelona: Ariel.

Yela, M. (1994). La enseñanza de la psicología en España. Papeles del colegio, 90, pp. 39-48.

Wagner, W. y Hayes, N. (2011). El discurso de lo cotidiano y el sentido común. España: Anthropos. 